\title{
Nimir O. Elbashir, Mahmoud M. El-Halwagi, loannis G. Economou, Kenneth R. Hall (Eds): Natural Gas Processing from Midstream to Downstream
}

\author{
Edlard R. Adlard ${ }^{1}$ \\ (c) Springer-Verlag GmbH Germany, part of Springer Nature 2019
}

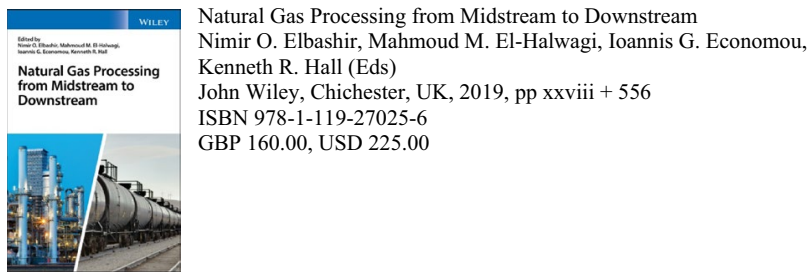

This large book is more of an encyclopedia than a textbook with 21 chapters and 57 authors, but as the title makes clear it is not comprehensive. To make it comprehensive would probably require another 500-page volume. The majority of the authors are from the USA which, not unsurprisingly, means that it is written in American English. It is a wellknown aphorism that Britain and America are two countries separated by a common language, which in practice means that some words in the US vocabulary are not in the English vocabulary. I was puzzled by the word "monetization" on the first page of the introductory chapter. This does not appear in my OED but according to Webster monetize means "to convert a non-generating asset into a source of revenue" which makes sense in the context. Webster states that it was first used in 1879-a mere yesterday in linguistic terms. There are contributors from half a dozen countries besides the USA but one notable absence is a contribution from any Russian author. Russia has vast natural gas deposits and currently supplies half of Western Europe (including the UK) with gas.

With such a large book it is not possible to give a synopsis of all the chapters but sufficient to say that they cover a wide range of topics from financial considerations to thermodynamic studies, to fracking, to modelling of processes. Currently, in the UK, fracking is a contentious subject so information on this topic is to be welcomed. The UK is making strenuous efforts to develop wind and solar power but it is going to be dependent on fossil fuels for a considerable time yet. My own personal opinion on fracking (for what it is worth) is that gas obtained by fracking is the least-worst option, better than oil and certainly better than coal. Gasfired electricity generating stations now operate with efficiencies of $50 \%$ or more-as opposed to coal-fired stations which can manage less than $40 \%$.

This is an important book which should be purchased by all those involved both with the oil industry and with environmental topics.

Publisher's Note Springer Nature remains neutral with regard to jurisdictional claims in published maps and institutional affiliations.
Edlard R. Adlard

e.adlard77@btinternet.com

1 Burton, UK 